\title{
Efficacy of Mefenamic acid and Ginger on Pain Relief in Primary Dysmenorrhea Among Basic Sciences Students of Nepalgunj Medical College
}

\author{
Ankita Singh 1 , Bijay Aryal², Sushma Deo ${ }^{3}$
}

\section{Author Info:}

${ }^{1}$ Lecturer, Department of Pharmacology, Nepalgunj Medical College and Teaching Hospital (Kathmandu University Affiliated), Chisapani, Nepal

${ }^{2}$ Professor, Department of Pharmacology, Karnali Academy of Health Sciences, Jumla, Nepal

\section{${ }^{3}$ Assistant Professor,} Department of Pharmacology, Janaki Medical College and Teaching Hospital (Tribhuvan University Affiliated), Janakpur, Nepal

\section{Corresponding Author:} Ankita Singh ankita.pharmacology@gmail.com

\section{ABSTRACT}

Background: Primary dysmenorrhea have been reported as the most common cause of regular absenteeism among young women. Pain affects daily activities and quality of life. The aim of the study was to compare the efficacy between mefenamic acid (Meftal) and ginger capsules (Remezy) among Basic Sciences Students of Nepalgunj Medical College (NGMC), Chisapani. Adverse effects, if any, were also observed in both Meftal and ginger group.

Method: This was a prospective cross-sectional study conducted from July 2018 to February 2019. Out of 104 students, 87 were suffering menstrual pain. These 87 individuals received Mefenamic acid (Meftal) $500 \mathrm{mg}$ twice a day for three days and the same 87 individuals, in their next month of period, took ginger capsules (Remezy) $500 \mathrm{mg}$ twice daily for three days. Medication was started on the first day of their menstruation. The severity of pain before and after the medication was recorded with the help of a multi-dimensional scoring system (MSS). All the data were directly entered into SPSS 20.0 and compiled, analyzed and expressed in tables and charts.

Results: Out of $104,87(83.7 \%)$ students had experienced menstrual pain. The mean \pm S.D age of the students was $19.64 \pm 1.02$ while the mean \pm S.D menarche age was $13.21 \pm 1.01$. The pain severity of dysmenorrhea was significantly reduced $(p<0.05)$ with both meftal and ginger intake in both the first and second months consecutively. However, a comparison of efficacy between the two medications showed no statistically significant difference $(p>0.05)$. Adverse effects were found to be significantly higher in students receiving meftal tablets.

Conclusion: A high proportion of students had dysmenorrhea. Similar efficacy of ginger and meftal was observed with minimal adverse effects in ginger. Findings suggest the need for educating students on appropriate and effective management of dysmenorrhea.

Keywords: Primary Dysmenorrhea, Meftal, Remezy, Multi-dimensional Scoring System (MSS), Nepalgunj Medical College (NGMC)

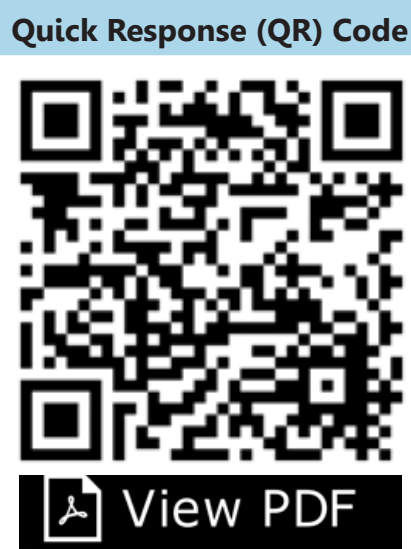

Scan Me for Full Text

\section{Article Info}

Received: 7 November 2019; Accepted: 21 January 2020; Published Online: 22 January 2020 How to cite this article in Vancouver Style?

Singh A, Aryal B, Deo S.Efficacy of Mefenamic acid and Ginger on Pain Relief in Primary Dysmenorrhea Among Basic Sciences Students of Nepalgunj Medical College.Europasian J Med Sci.2020;2(1):4-10. https://doi.org/10.46405/ejms.v2i1.27

Conflict of Interest: None Declared;

\section{Disclaimer}

Source of Support: Nil

Copyright: $(2020$ by author(s). This is an open access article distributed under the terms of the Creative Commons Attribution International License 4.0 (http://creativecommons.org/licenses/ by/4.0/) which permits unrestricted use, distribution, and reproduction in any medium, provided the original work is properly cited.

Publisher's Note:

The Europasian Journal of Medical Sciences (EJMS) remains neutral with regard to jurisdictional claims in published articles and institutional affiliations. 


\section{INTRODUCTION}

Dysmenorrhea is the most commonly reported menstrual disorder. More than one-half of women who menstruate have some pain for 1-2 days each month. ${ }^{1}$ According to a World Health Organisation (WHO) systemic review, the prevalence rate of dysmenorrhea can range from $16.8 \%$ to $81 \%{ }^{2}$ It is associated with a negative impact on social, academic, and sports activities of many female adolescents. ${ }^{3}$ Primary and secondary are two categories of dysmenorrhea. Primary dysmenorrheais presented with acute pain that comes from having a menstrual period, or "menstrual cramps." Pain is lessened with age or after childbirth. Disorders like endometriosis or fibroids can lead to secondary dysmenorrhea. Overtime, pain tends to get worse rather than better. ${ }^{4-6}$

Studies suggests that Non-steroidal antiinflammatory drugs (NSAIDs) are mainstay treatment for managing the pain of primary dysmenorrhea, but they commonly cause adverse effects, including indigestion, headaches and drowsiness. ${ }^{7-9}$ Considering the safety, tiaprofenic acid and mefenamic acid were indicated to be safest NSAIDs drugs while indomethacin were likely to cause mild gastrointestinal discomfort. ${ }^{8}$ Mefenamic acid (Meftal) is widely used over the counter drug among the Basic Medical Sciences students. Ginger, on the other hand, has been proved to reduce the menstrual pain significantly and be as effective as other NSAIDs group of drugs. ${ }^{10-12}$

This study investigates the efficacy of meftal and ginger in primary dysmenorrhea among Basic Medical Sciences students. A comparison between the efficacy of these two drugs was made using the multidimensional scoring system, which measures the severity of pain. This study also observes the presence of adverse effects in both medications, if any. The objective of this study is to compare the efficacy of mefenamic acid and ginger in primary dysmenorrhea and observe the presence of adverse effects if any.

\section{MATERIALS AND METHODS}

This was a prospective cross-sectional study conducted in Nepalgunj Medical College, Chisapani,

Table 1: Verbal Multidimensional Scoring System for the assessment of dysmenorrhea severity.

\begin{tabular}{|c|c|c|c|}
\hline Severity grading & $\begin{array}{l}\text { Working } \\
\text { ability }\end{array}$ & $\begin{array}{l}\text { Systemic } \\
\text { symptoms }\end{array}$ & Analgesics \\
\hline $\begin{array}{l}\text { Grade 0: } \\
\text { Menstruation is not painful and daily activity is unaffected. }\end{array}$ & Unaffected & None & $\begin{array}{l}\text { None } \\
\text { required }\end{array}$ \\
\hline $\begin{array}{l}\text { Mild (Grade 1): } \\
\text { Menstruation is painful but seldom inhibits normal activity; } \\
\text { analgesics are seldom required; mild pain. }\end{array}$ & $\begin{array}{l}\text { Rarely } \\
\text { affected }\end{array}$ & None & $\begin{array}{l}\text { Rarely } \\
\text { required }\end{array}$ \\
\hline \multicolumn{4}{|l|}{ Moderate (Grade 2): } \\
\hline $\begin{array}{l}\text { Daily activity is affected; analgesics required and give } \\
\text { sufficient relief so that absence from school is unusual; } \\
\text { moderate pain. }\end{array}$ & $\begin{array}{l}\text { Moderately } \\
\text { affected }\end{array}$ & Few & Required \\
\hline \multicolumn{4}{|l|}{ Severe (Grade 3): } \\
\hline $\begin{array}{l}\text { Activity clearly inhibited, poor effect of analgesics; } \\
\text { vegetative symptoms (headache, fatigue, vomiting and } \\
\text { diarrhea); severe pain. }\end{array}$ & $\begin{array}{l}\text { Clearly } \\
\text { inhibited }\end{array}$ & Apparent & Poor effect \\
\hline
\end{tabular}




\begin{tabular}{|c|c|c|c|c|}
\hline \multirow{2}{*}{ Age } & \multicolumn{2}{|c|}{ Dysmenorrhea } & \multirow[t]{2}{*}{ Total } & \multirow{3}{*}{$\begin{array}{c}\text { P-value } \\
>0.05\end{array}$} \\
\hline & Yes & No & & \\
\hline $18-20$ & $\begin{array}{c}67 \\
(82 \%)\end{array}$ & $\begin{array}{c}15 \\
(18.3 \%)\end{array}$ & 82 & \\
\hline \multirow[t]{2}{*}{$21-23$} & $\begin{array}{c}20 \\
(91 \%)\end{array}$ & $\begin{array}{c}2 \\
(9.1 \%)\end{array}$ & 22 & \\
\hline & 87 & 17 & 104 & \\
\hline
\end{tabular}

between July 2018 to February 2019. Informed consent was taken from all the Basic Sciences Students enrolled in the study. All the recorded data were highly confidential. Data were collected in two parts. In the first part, students were asked about their socio-demographic profile(age, study batch, nationality) and menstrual characteristics (menarche age, menstrual regularity, menstrual cycle duration, family history of dysmenorrhea, frequency of dysmenorrhea; if it occurs every single month,alternative month, occurs rarely or had never occurred till date, severity of pain experienced; none, mild, moderate or severe). Severity of pain was recorded using a Multidimensional Scoring System (MSS) (shown in Table 1)before and after the intake of meftal tablets and ginger capsules.

The second part of the data collection included the intake of mefenamic acid (Meftal) $500 \mathrm{mg}$ twice daily for three days in 87 individuals who were suffering from dysmenorrhea. The same 87 individuals who suffered in the first monthwas asked to take ginger capsules (Remezy) $500 \mathrm{mg}$ twice daily for 3 consecutive days in the second month of their period. The severity of pain was assessed using MSS before and after meftal and ginger intake. MSS is defined as mild, moderate, severe based on pain and limited activities as shown in Table 1. All the data were statistically analyzed using SPSS version 20 and Microsoft Excel and expressed in tables and charts.

\section{RESULTS}

Out of 104 students enrolled in the study, 87 (83.7\%) of them had dysmenorrhea. Age ranged from 18 to 23 years with the mean \pm S.D age of $19.64 \pm 1.02$ years as shown in Table 2 below.No statistically significant difference with the pvalue $>0.05$ was found between two variables; Dysmenorrhea experience and age range.

Students of three years (from 2016 batch to 2018 batch) were observed. Out of 37 students of Batch 2016, 27 (73\%) of them suffer, out of 43 students of batch 2017, 41 (95.3\%) suffers and out of 24 students of batch 2018, 19 (79.2\%) of students suffers from menstrual pain. With the $p$ value $<0.05$, ahighly statisticaly significant difference was found in students of batch 2017 suffering dysmenorrhea.

Out of 41 Indian students, 29 (70.73\%) students suffered dysmenorrhea and out of 63 Nepali students, 58 (92.06\%) suffered dysmenorrhea. This is statistically significant with the p-value $<0.05$. $40.4 \%$ of students had a history of dysmenorrhea in their family and $59.6 \%$ of students have no history in the family. With the help of Multidimensional Scoring System (MSS), the severity of the menstrual pain was assessed in these two consecutive months. Figure 1 represents the severity of pain (i.e. mild pain, moderate pain and severe pain) after the meftal intake in the first month and before ginger intake in the second month. With the $p$ value $=0.79$ (i.e. $p>0.05$ ) No significant difference in pain severity is observed before medications in

Fig 1:

Severity of pain before meftal/ginger therapy

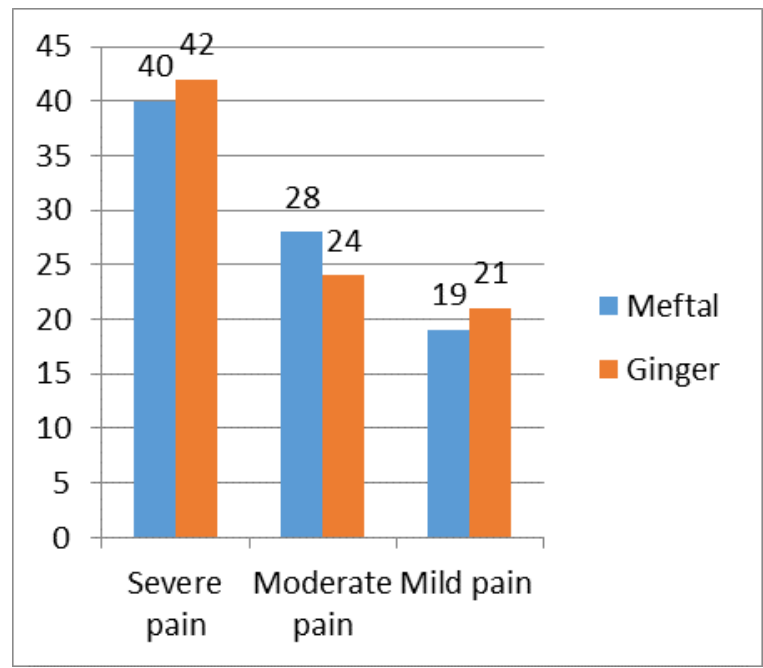


these two consecutive months. In 87 students with primary dysmenorrhea, 40 (45.98\%) students had severe pain in the first month of meftal group and $42(48.28 \%)$ students had severe pain in the second month of ginger group. In the first month, meftal relieved 14 (16.09\%) students completely with no pain, 20 (22.99\%) had mild pain and 6 (6.89\%) still had moderate pain.

Similarly, in the second month of ginger group, ginger relieved 16 (18.39\%) students with no pain, 18 (20.69\%) had mild pain and 8 (9.19\%) still had moderate pain. With the $p$-value of 0.78 (i.e. $p>0.05$ ), no significant difference was found in the severe

Figure 2: Reduction in pain in a severe case in both the meftal/ginger group

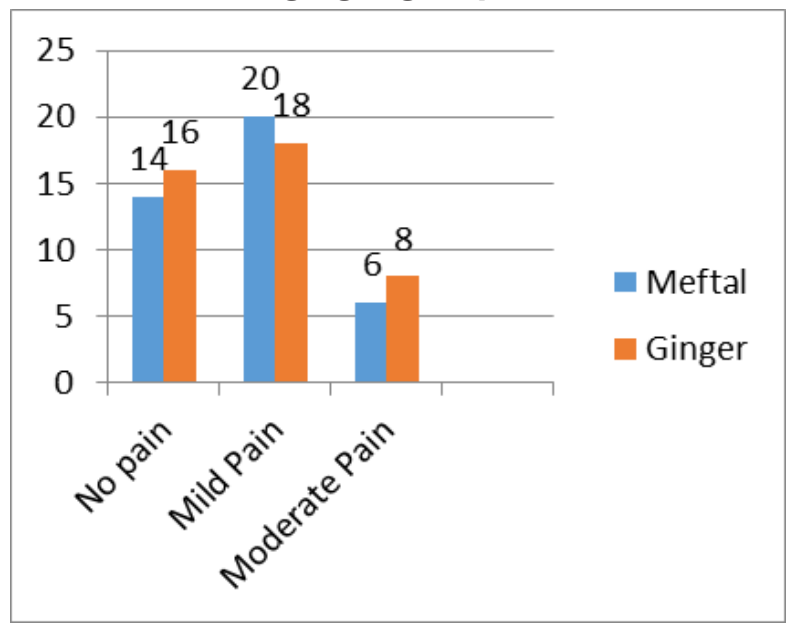

case in meftal and ginger group in relieving the pain of menstruation. In the first month of meftal group, 28 (32.18\%) students had moderate pain in which 22 (25.29\%) were completely relieved and 6 (6.89\%) still had mild pain. Similarly, in the second month, 24 (27.59\%) had moderate pain in which 21 (24.14\%) had no pain afterward and 3 (3.45\%) had mild pain. With the p-value of 0.39 (i.e. $p>0.05$ ), No significant difference was found in these two medications for pain relief in a moderate case. Out of $19(21.84 \%)$ students who had mild pain in the first month of meftal group, 17 (19.54\%) had no pain and 2 (2.30\%) still had mild pain afterward. Similarly, in the second month, 21 (24.14\%) had mild pain in which 19 (21.84\%) had no pain afterward and $2(2.30 \%)$ still had mild pain. With the $\mathrm{p}$-value of 0.916 (i.e. $p>0.05$ ), No significant difference was found in these two medications for pain relief in Figure 3: Pain Relief in moderate case of both meftal/ginger group

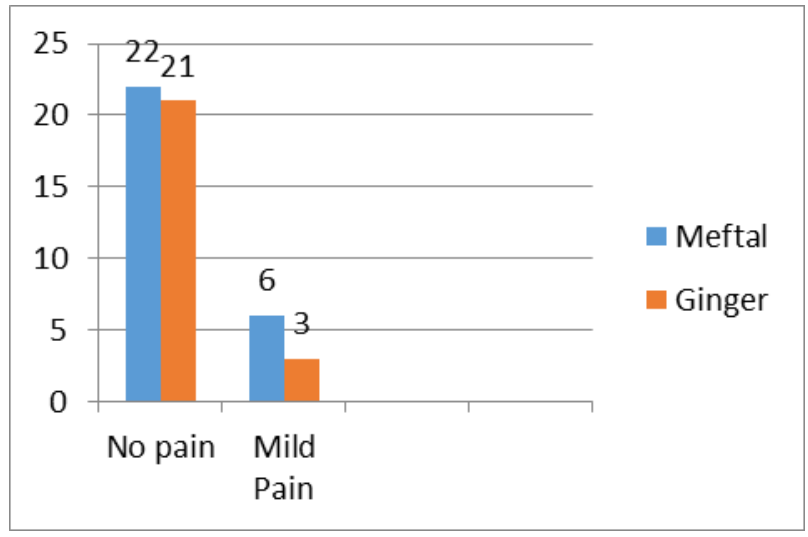

Figure 4: Pain relief in a mild case in both meftal/ ginger group

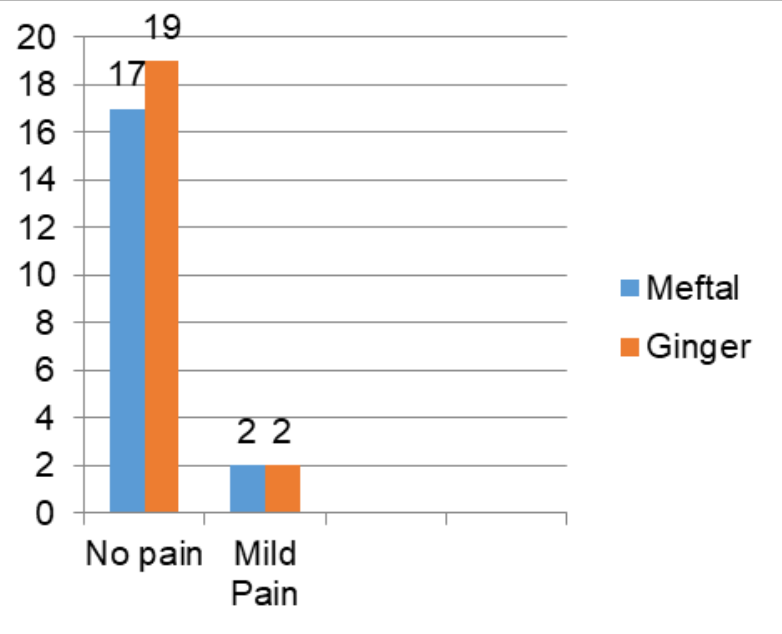

the mild case. In meftal group, out of 40 (45.98\%) students who had severe pain, 14 (16.09\%) got relief completely with no pain. 22 (25.29\%) moderate cases were there in which 22 (25.29\%) had no pain afterward. Among 19 (21.84\%) students who had mild pain, 17 (19.54\%) had no pain after meftal intake. With the $p$ value $<0.001$, a highly statistically significant difference was observed in the efficacy of meftal group in relieving the pain. 
Figure 5: Pain relief in meftal group

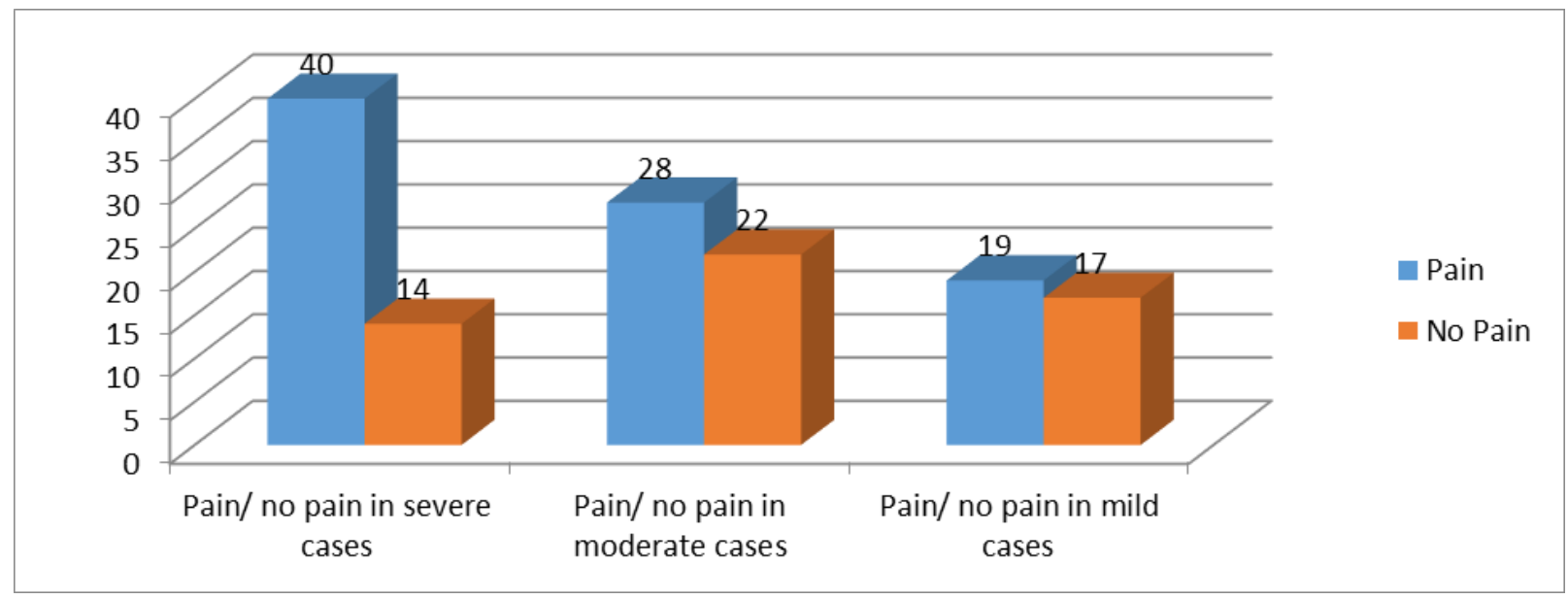

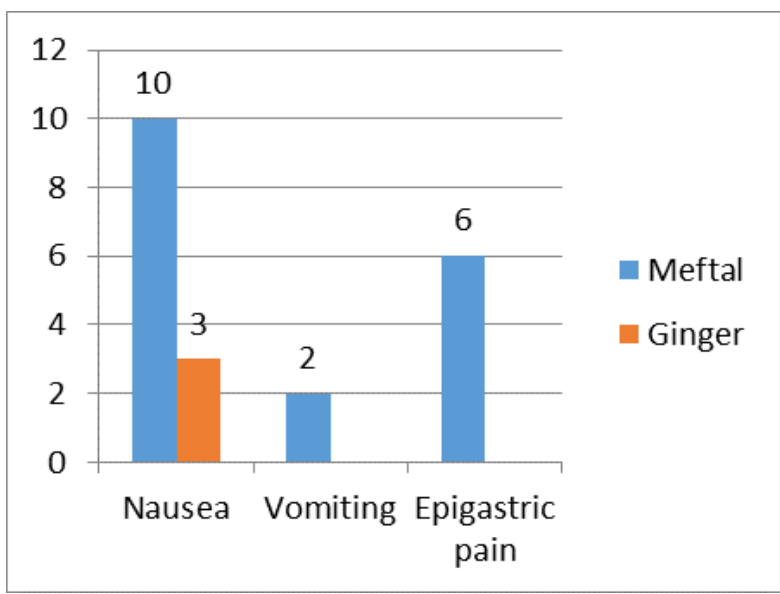

Figure 7: Adverse effects observed in meftal/ ginger intake

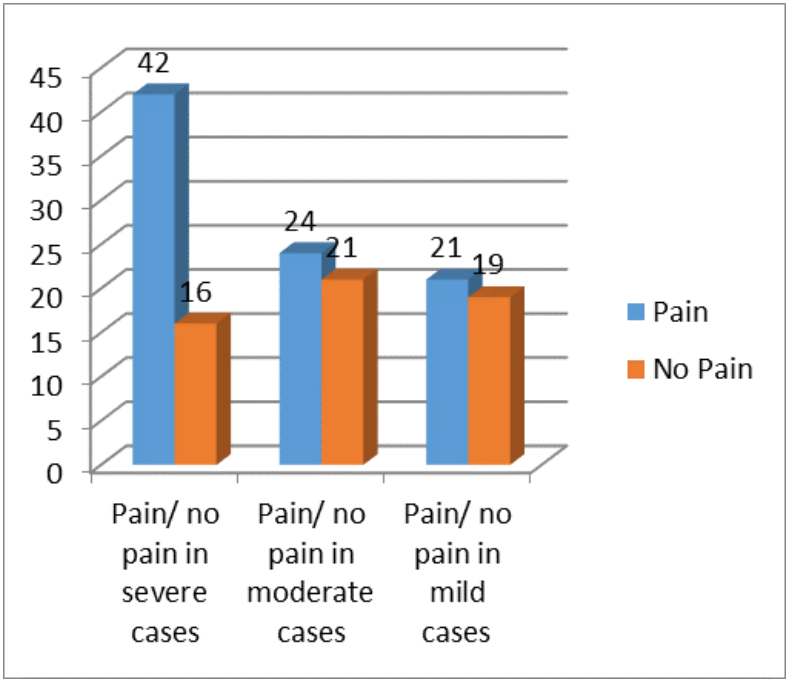

Figure 6: Pain relief in the ginger group
In ginger group, out of 42 (48.28\%) students with severe pain, 16 (18.39\%) had no pain after ginger intake. 24 (27.59\%) moderate cases were there in which 21 (24.14\%) were relieved completely afterward. Similarly, out of $21(24.14 \%)$ mild pain cases, 19 (21.84\%) students had no pain afterward. With the p-value <0.001, a highly statistical difference was observed in ginger for pain-relieving effect.

Out of 87 students, 16 (18.39\%) students suffered from the adverse effects of meftal. 10 (11.49\%) students had severe nausea in which $2(2.30 \%)$ even vomited. 6 (6.89\%) of them had abdominal discomfort and epigastric pain. Only 3 (3.45\%) individuals was nauseated with the ginger group out of 87 individuals. With the $p$ value $<0.05$, a highly statistical difference was observed in the favor of ginger group having minimal adverse effects.

\section{DISCUSSION}

Discussion Among the 104 participants, the overall prevalence of dysmenorrhea was $83.7 \%$ which was in agreement with the prevalence rate reported by University of Gondar students, Universitaria Policlinico of Modena, and Private University in Ogun State, which were $77.6 \%, 84.1 \%$, and $78.1 \%$ respectively. ${ }^{13-15}$ 
In this study, $45.98 \%$ in meftal group and $48.28 \%$ in the ginger group described their pain as severe. Similarly, $32.18 \%$ in meftal and $27.58 \%$ in ginger group describe their pain as moderate which is similar to the study by Unsal A et al ${ }^{16}$ where approximately two-thirds of the women (66.2\%) described their dysmenorrhea as severe and moderate. A study by Burnett et $\mathrm{al}^{17}$ in Canada also reported that sixty percent of the women with primary dysmenorrhea described their pain as moderate or severe.This indicates that dysmenorrhea is still an important public health problem and most of the females experience severe or moderate dysmenorrhea.

NSAIDs are the mainstay treatment for managing the menstrual pain; mefenamic acid, being the widely used and preferred drug in primary dysmenorrhea. ${ }^{7,8}$ Our findings suggests that no significant difference in pain reliefwas found between ginger and meftal in terms of efficacy. However, significantly fewer side effects were observed in ginger. This finding is similar to the study done by Shirvani MA et al. ${ }^{11}$ who concludes that ginger is as effective as mefenamic acid on pain relief in primary dysmenorrhea. Ginger does not have adverse effects and is an alternative treatment for primary dysmenorrhea. Rahnama et al ${ }^{12}$ also suggest that ginger had a statistically significant effect on relieving the intensity of menstrual pain. Similarly, Ozgoli et al ${ }^{18}$ also supportsour findings of the superiority of ginger, being comparable to the established drug like mefenamic acid in relieving menstrual pain in women.

Larger sample size targeting many individuals can provide more reliable and valuable data. Different factors that may affect the menstrual outcome like obesity, smoking and stress were not taken into consideration.

\section{CONCLUSION}

Conclusion The prevalence of primary dysmenorrhea was high in our study. This study suggests that the both ginger and mefenamic acid were effective for relieving the painand when compared with each other, ginger was as effective as mefenamic acid on pain relief in primary dysmenorrhea. Infact, significantly few side effects were observed with ginger.

\section{REFERENCES}

1. Proctor $M$, Farquhar C. Diagnosis and management of dysmenorrhoea. BMJ. 2006.13; 332(7550): 11348. [CrossRef] [GoogleScholar] [PubMed]

2. Latthe $P$, Latthe $M$, Say L, Gülmezoglu M, Khan KS. WHO systematic review of prevalence of chronic pelvic pain: a neglected reproductive health morbidity. BMC Public Health. 2006 Jul 6; 6: 177. [CrossRef] [GoogleScholar] [PubMed]

3. Banikarim C, Chacko MR, Kelder SH. Prevalence and impact of dysmenorrhea on Hispanic female adolescents. Arch Pediatr Adolesc Med. 2000;154(12):1226-9. [CrossRef] [GoogleScholar] [PubMed]

4. lacovides S, Avidon I, Baker FC. What we know about primary dysmenorrhea today: a critical review. Hum Reprod Update. 2015 NovDec;21(6):762-78. [CrossRef] [GoogleScholar] [PubMed]

5. Payne LA, Rapkin AJ, Seidman LC, Zeltzer LK, Tsao JC. Experimental and procedural pain responses in primary dysmenorrhea: a systematic review. J Pain Res. 2017.12;10:2233-2246. [CrossRef] [GoogleScholar] [PubMed]

6. Latthe $P M$, Champaneria $R$, Khan KS Dysmenorrhoea. BMJ Clin Evid. 2011 Feb 21;2011. PMid: 21718556. [PubMed] [FullText]

7. Marjoribanks J, Proctor M, Farquhar C, Derks RS. Nonsteroidal anti-inflammatory drugs for dysmenorrhoea. Cochrane Database Syst Rev. 2010 Jan 20; (1): CD001751. [CrossRef] [GoogleScholar] [PubMed]

8. Feng $X$, Wang $X$. Comparison of the efficacy and safety of non-steroidal anti-inflammatory drugs for patients with primary dysmenorrhea: A network meta-analysis. Mol Pain. 2018;14: 17448806918770320. [CrossRef] [PubMed] 
9. Camlibel M, Erdur B, Yilmaz A, Ozen M, Uyanik A. Comparison of the Effects of Piroxicam and Diclofenac Sodium as Treatments for Primary Dysmenorrhea. Med Sci Monit. 2019; 25:157-164. [CrossRef] [GoogleSchoar] [PubMed]

10. Daily JW, Zhang X, Kim DS, Park S. Efficacy of ginger for alleviating the symptoms of primary dysmenorrhea: A systematic review and metaanalysis of randomized clinical trials. Pain Med. 2015; 16(12): 2243-55. [CrossRef] [GoogleScholar] [PubMed]

11. Shirvani MA, Motahari-Tabari N, Alipour A. The effect of mefenamic acid and ginger on pain relief in primary dysmenorrhea: a randomized clinical trial. Arch Gynecol Obstet. 2015 Jun; 291(6): 1277-81. [CrossRef] [GoogleScholar] [PubMed]

12. Rahnama $P$, Montazeri A, Huseini HF, Kianbakht $S$, Naseri M. Effect of Zingiber officinale R. rhizomes (ginger) on pain relief in primary dysmenorrhea: a placebo randomized trial. BMC Complement Altern Med. 2012; 12: 92.[CrossRef] [GoogleScholar] [PubMed]

13. Gebeyehu MB, Mekuria AB, Tefera YG, Andarge DA, Debay YB, Bejiga GS, Gebresillassie BM. Prevalence, impact, and management practice of dysmenorrhea among university of gondar students, northwestern ethiopia: A cross-sectional study. Int J Reprod Med. 2017; 2017: 3208276.

[CrossRef] [GoogleScholar] [PubMed]

14. Farotimi A. A., Esike J., Wozichi C. U., Ojediran T.D., Ojewole F. O. Knowledge, attitude, and healthcare-seeking behavior towards dysmenorrhea among female students of a private university in Ogun state, Nigeria. J Basic Clin Reprod Sci. 2015; 4(1): 33-38. [FullText] [GoogleScholar]

15. Grandi G., Ferrari S., Xholli A., et al. Prevalence of menstrual pain in young women: what is dysmenorrhea? Journal of Pain Research. 2012; 5: 169-174.

[CrossRef] [GoogleScholar] [PubMed]

16. Unsal A, Ayranci U, Tozun M, Arslan G, Calik E. Prevalence of dysmenorrhea and its effect on quality of life among a group of female university students. Ups J Med Sci. 2010 May; 115(2): 138-45. [CrossRef] [GoogleScholar] [PubMed]
13. Gebeyehu MB, Mekuria AB, Tefera YG, Andarge DA, Debay YB, Bejiga GS, Gebresillassie BM. Prevalence, impact, and management practice of dysmenorrhea among university of gondar students, northwestern ethiopia: A cross-sectional study. Int J Reprod Med. 2017; 2017: 3208276. [CrossRef] [GoogleScholar] [PubMed]

14. Farotimi A. A., Esike J., Wozichi C. U., Ojediran T.D., Ojewole F. O. Knowledge, attitude, and healthcare-seeking behavior towards dysmenorrhea among female students of a private university in Ogun state, Nigeria. J Basic Clin Reprod Sci. 2015; 4(1): 33-38. [FullText] [GoogleScholar]

15. Grandi G., Ferrari S., Xholli A., et al. Prevalence of menstrual pain in young women: what is dysmenorrhea? Journal of Pain Research. 2012; 5: 169-174. [CrossRef] [GoogleScholar] [PubMed]

16. Unsal A, Ayranci U, Tozun M, Arslan G, Calik E. Prevalence of dysmenorrhea and its effect on quality of life among a group of female university students. Ups J Med Sci. 2010 May; 115(2): 138-45. [CrossRef] [GoogleScholar] [PubMed]

17. Burnett MA, Antao V, Black A, Feldman K, Grenville A, Lea R, Lefebvre G,Pinsonneault O, Robert M. Prevalence of primary dysmenorrhea in Canada. J Obstet Gynaecol Can. 2005 Aug; 27(8): 765-70. [CrossRef] [GoogleScholar] [PubMed]

18. Ozgoli G, Goli M, Moattar F. Comparison of effects of ginger, mefenamic acid,and ibuprofen on pain in women with primary dysmenorrhea. J Altern Complement Med. 2009 Feb; 15(2): 129-32. [CrossRef] [GoogleScholar] [PubMed] 